\title{
Influence of Composite Non Magnetic Ions (Cd-Ti) Doping on Structural and Electrical Properties of Li-Mn Ferrite
}

\author{
Vidya J. Deshmukh ${ }^{1}$, Pragati S. Jadhav ${ }^{2}$, Ketaki K. Patankar ${ }^{2 *}$, Sharad S. Suryawanshi ${ }^{3}$, Vijaya R. Puri ${ }^{4}$ \\ ${ }^{1}$ Ramkrishna Paramhansa Mahavidyalaya, Osmanabad College, Osmanabad, India; ${ }^{2}$ Physics Department Rajaram College, Kolhapur, \\ India; ${ }^{3}$ Physics Department, Solapur University, Solapur, India; ${ }^{4}$ Physics Department, Shivaji University, Kolhapur, India. \\ Email: *ketakiketan@yahoo.com
}

Received May $6^{\text {th }}, 2012$; revised July $23^{\text {rd }}, 2012$; accepted August $16^{\text {th }}, 2012$

\begin{abstract}
The Li-Mn ferrites with composite divalent and tetravalent non-magnetic ions doping were prepared by ceramic method and studied for the first time to investigate their structural and electrical properties. It has been confirmed from the studies that these materials result in properties suitable for microwave applications. The structural properties have confirmed the formation of cubic spinel ferrite and the substitutions of non magnetic ions have resulted in increase of unit cell dimensions and hence the grain size with increase in dopant content. An IR study asserts the same. Electrical Properties show increase in dc resistivity and decrease in dielectric loss tangent with increase in dopant concentration.
\end{abstract}

Keywords: Electronic Materials; Magnetic Ceramics; Electrical Characterization; Powder Diffraction

\section{Introduction}

Li ferrite is becoming increasingly attractive for microwave applications replacing garnets and other spinel ferrites [1-3]. Microwave devices such as circulators, isolators, magnetostatic resonators, filters, switches, limiters and tunable electroptic modulators are the microwave applications of Li ferrites [4]. Recent exponential growth in microwave communication through mobile and satellite communications has further stressed the worldwide need for extremely low-loss and economical microwave devices using ferrite materials. In preparation of microwave ferrite materials, particular attention should be given to the purity of the raw materials, stoichiometry of the composition and porosity as well as grain characteristics of the final product. Characteristics of various microwave ferrites have been minutely reported by Voronkov et al. [5]. The emergence of Li ferrite as a competent material in microwave devices has resulted from some appropriate chemical substitutions made in it, which in turn result in low dielectric loss tangent, a low magnetic loss tangent at the operating bias field, a low coercive force and a large remanence ratio [6-8]. Low dielectric and magnetic losses are the essential requisites for microwave applications Small amounts of $\mathrm{Mn}^{3+}$ is added to microwave Li ferrites to ensure an acceptably low dielectric loss tangent [9]. Moreover, manganese addition also alter the hysteresis property, reduces magnetocrystalline anisotropy and magnetostriction in ferrites [9].

"Corresponding author.
Non magnetic ions like $\mathrm{Cd}^{2+}$ and $\mathrm{Ti}^{4+}$ substitutions have been found to be most suitable to obtain high resistivity $[10,11]$. The site occupancies of the various cations known from earlier works are given as follows. $\mathrm{Li}^{1+}$ has strong preference for B-Site [12], $\mathrm{Cd}^{2+}$ has strong preference for A site [1], $\mathrm{Ti}^{4+}$ also has strong preference for B-site [13], $\mathrm{Fe}^{2+}$ has strong preference for B-site [1] and $\mathrm{Mn}^{3+}$ has strong preference for B-site [14]. From the above survey, it can be envisaged that investigations on the electrical properties of composite non-magnetic ions doping in Li-Mn ferrite may lead to more interesting results as the studies on their independent doping in Lithium ferrites have already resulted in properties suitable for microwave applications [10,11].

In this view, the present paper aims to communicate structural and electric properties in $\mathrm{Li}_{0.35} \mathrm{Cd}_{\mathrm{x}} \mathrm{Ti}_{\mathrm{x}} \mathrm{Mn}_{0.1}$ $\mathrm{Fe}_{2.55-2 \mathrm{x}} \mathrm{O}_{4}$ where $\mathrm{x}$ varies from 0 to 0.5 .

\section{Experimental}

Six samples of different compositions were prepared by standard ceramic technique using pure metal oxides in the form of a series $\mathrm{Li}_{0.35} \mathrm{Cd}_{\mathrm{x}} \mathrm{Ti}_{\mathrm{x}} \mathrm{Mn}_{0.1} \mathrm{Fe}_{2.55-2 \mathrm{x}} \mathrm{O}_{4}$ with $\mathrm{x}=$ $0.0,0.1,0.2,0.3,0.4$ and 0.5 . AR grade chemicals of $\mathrm{Li}_{2} \mathrm{CO}_{3}, \mathrm{CdO}, \mathrm{TiO}_{2}, \mathrm{Mn}_{2} \mathrm{O}_{3}$ and $\mathrm{Fe}_{2} \mathrm{O}_{3}$ were used for the preparation of various compositions in the above ferrite series. These oxides were weighed in the required mole proportions using a single pan balance having least count $0.001 \mathrm{gm}$ and mixed thoroughly in the agate-mortar in acetone for about $2 \mathrm{hrs}$. The mixture was sieved using a 
sieve of mesh size 200 micron. The mixture of each composition was preheated in platinum crucible and were presintered at $300^{\circ} \mathrm{C}$ for 2 hours and followed by 600 Influence of Composite Non Magnetic ions (Cd-Ti) Doping on Structural and Electrical Properties of $\mathrm{Li}-\mathrm{Mn}$ Ferrite for $4 \mathrm{hrs}$ and finally sintered at $1000^{\circ} \mathrm{C}$ for 8 hours.

X-ray Diffractograms of various compositions were obtained using $\mathrm{X}$ ray diffractometer Model PW 3710. The various parameters used for $\mathrm{X}$ ray diffraction were Target $-\mathrm{Cu} \mathrm{K} \mathrm{K}_{\alpha}$; Wavelengths $\lambda_{1}=1.54056 \AA$ and $\lambda_{2}=$ $1.54439 \AA$; Rate of Scanning - $2^{\circ} / \mathrm{min}$ and scanning angle range $2 \theta-20^{\circ}$ to $90^{\circ}$. Micrographs of various samples were obtained using the scanning electron microscope SEM (model JSM-6360A). IR absorption peaks of various compositions were studied using PerkinElmer IR spectrometer (Model 783) with $\mathrm{KBr}$ as a solvent. DC resistivities of various prepared samples were studied using two probe set up. Dielectric constant and loss tangent in the frequency range $100 \mathrm{~Hz}-1 \mathrm{MHz}$ were also measured using HP LCR meter 4284A model.

\section{Results and Discussion}

The X-Ray diffraction patterns for $\mathrm{Li}_{0.35} \mathrm{Cd}_{\mathrm{x}} \mathrm{Ti}_{\mathrm{x}} \mathrm{Mn}_{0.1}$ $\mathrm{Fe}_{2.55-2 \mathrm{x}} \mathrm{O}_{4}$ system show sharp peaks indicating formation of single phase spinel ferrite for all compositions. However trace amount of $\alpha-\mathrm{Fe}_{2} \mathrm{O}_{3}$ phase is found for $\mathrm{x}=0.3$ sample. Hence the XRD of $\mathrm{x}=0.3$ composition is given in the Figure 1. The $\alpha-\mathrm{Fe}_{2} \mathrm{O}_{3}$ phase is formed because at higher sintering temperature $\left(>500^{\circ} \mathrm{C}\right)$ there is possibility for a fraction of ferric oxide to get converted into $\alpha-\mathrm{Fe}_{2} \mathrm{O}_{3}$. The presence of such a phase in different ferrite is already reported by earlier workers [15].

The lattice parameter increases with increasing the content of $\mathrm{Cd}^{2+}$ and $\mathrm{Ti}^{4+}$ ions and is shown in Figure 2. This is in accordance with Vegard's law. The $\mathrm{Cd}^{2+}$ ions have larger ionic radius $(0.97 \AA)$ as compared to $\mathrm{Fe}^{3+}$

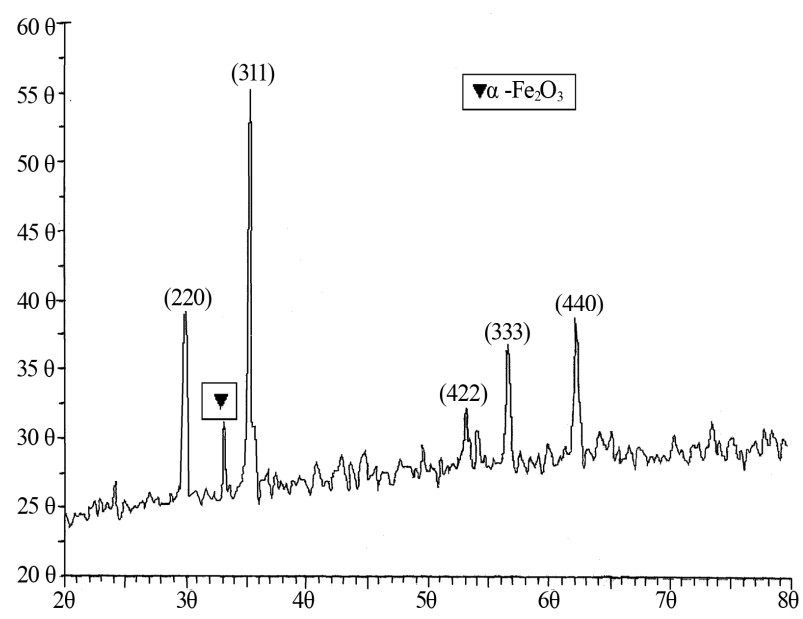

Figure 1. $\mathrm{Fe}_{2} \mathrm{O}_{3}$ pattern XRD of $\mathrm{Li}_{0.35} \mathrm{Cd}_{0.3} \mathrm{Ti}_{0.3} \mathrm{Mn}_{0.1} \mathrm{Fe}_{1.95} \mathrm{O}_{4}$.

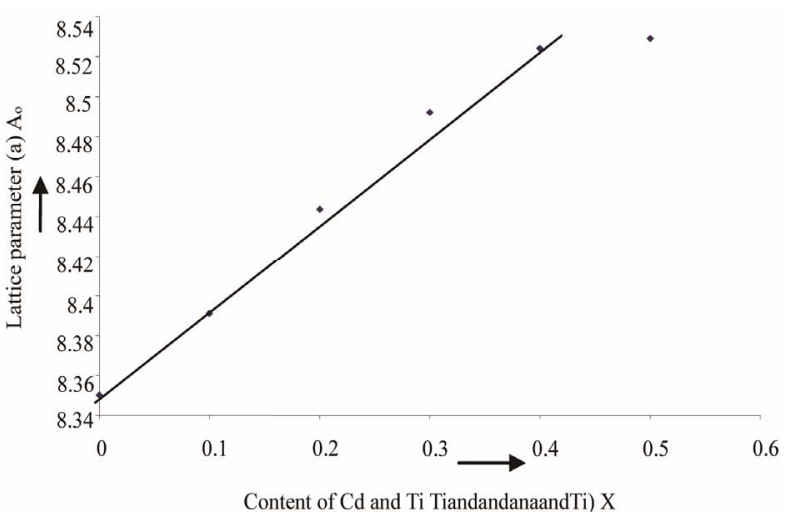

Figure 2. Variation of lattice parameter with $\mathrm{Cd}$ and $\mathrm{Ti}$ content $[\mathrm{x}]$ in $\mathrm{Li}_{0.35} \mathrm{Cd}_{\mathrm{x}} \mathrm{Ti}_{\mathrm{x}} \mathrm{Mn}_{0.1} \mathrm{Fe}_{2.55-2 \mathrm{x}} \mathrm{O}_{4}$ series.

$(0.65 \AA), \mathrm{Ni}^{2+}(0.74 \AA)$ and $\mathrm{Li}^{1+}(0.71 \AA)$ ions. The $\mathrm{Cd}^{2+}$ ions successively replace $\mathrm{Fe}^{3+}$ ions on $\mathrm{A}$-site this results in an increase of lattice parameter with $\mathrm{Cd}$ content. Same is true for Ti ions at B-sites. Similar results were obtained when $\mathrm{Cd}$ and $\mathrm{Ti}$ were separately doped in $\mathrm{Li}$ ferrite $[10,11]$. The compositional variations however suggest that the lattice parameters for composite non-magnetic ions doping is increased to larger extent in comparison to their separate doping in ferrites.

The SEM technique was studied to understand the surface morphology of the samples. All compositions have grains with sharp boundaries indicating that grains are fully developed, well packed, crack free with clear grain boundaries. The grain boundaries are district and grains are closely packed in some cases which suggest that compositions exhibit high density values. The SEM images denoted by a, b, c, d, e, and f shows micrographs for compositions $\mathrm{x}=0.0,0.1,0.2,0.3,0.4$, and 0.5 . With the addition of $\mathrm{Cd}-\mathrm{Ti}$ ions the average grain size increases as shown in the Figures 3(a)-(f). The increase in grain diameter with $\mathrm{Cd}$ and $\mathrm{Ti}$ content is attributed to the smaller solid solubility of lithium in the samples. It is obvious from the generic formula.

The IR spectra of one representative member of ferrite series i.e. $\mathrm{x}=0.3$ is shown in Figure 4. The IR absorption bands were observed in the range $600 \mathrm{~cm}^{-1}$ to 400 $\mathrm{cm}^{-1}$. The absorption bands obtained in the present investigation are found to be in the range reported for many other lithium containing ferrites $[16,17]$. The difference in band position $v_{1}$ and $v_{2}$ is expected because the $\mathrm{Fe}^{3+}-\mathrm{O}^{2-}$ distance for B site $(0.199 \mathrm{~nm})$ is different from that of A site $(0.189 \mathrm{~nm})$. The tetrahedral vibrations are of bond stretching type while octahedral vibrations are of bond bending type. These types of vibrations also affect the absorption frequency. The octrahedral complex band is found to be suppressed with increase in composite nonmagnetic ions content in the ferrite. This can be attributed to increase in the lattice parameter and average grain size with increase in $\mathrm{Cd}-\mathrm{Ti}$ content. 


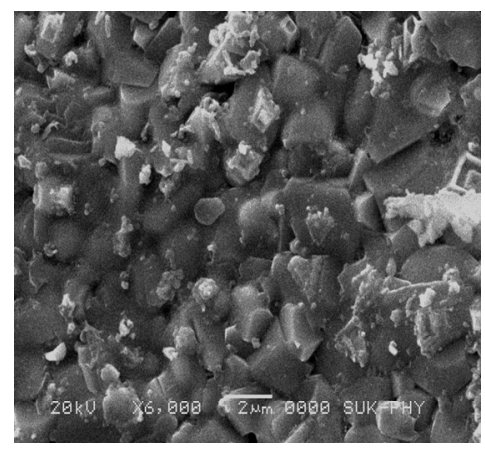

(a)

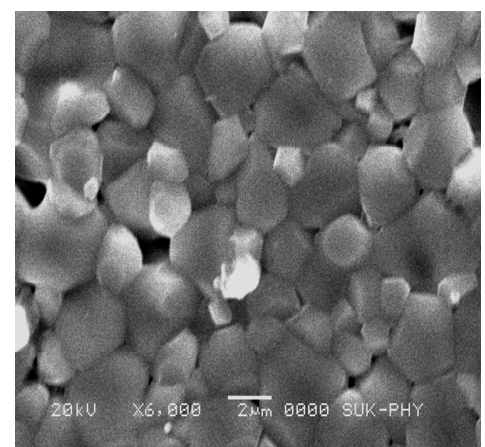

(d)

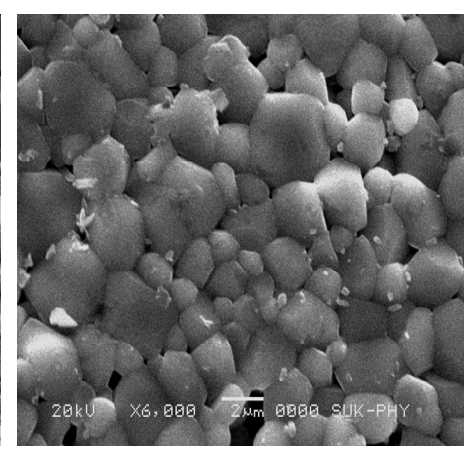

(b)

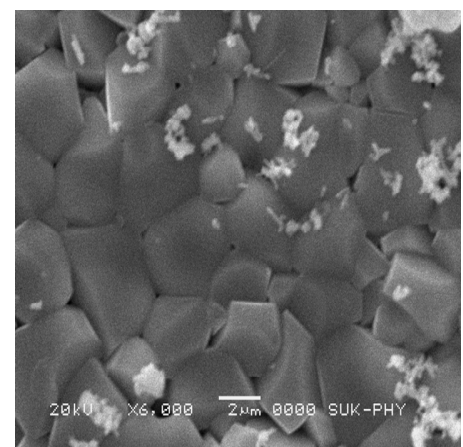

(e)

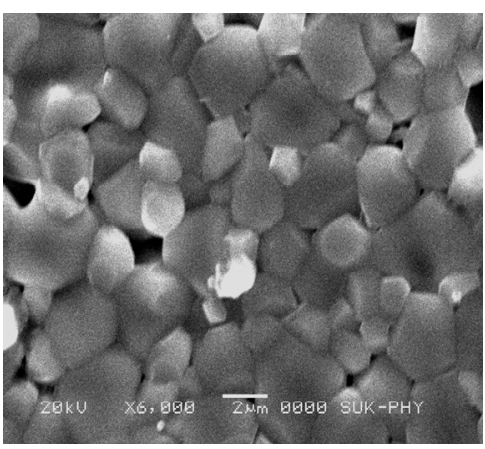

(c)

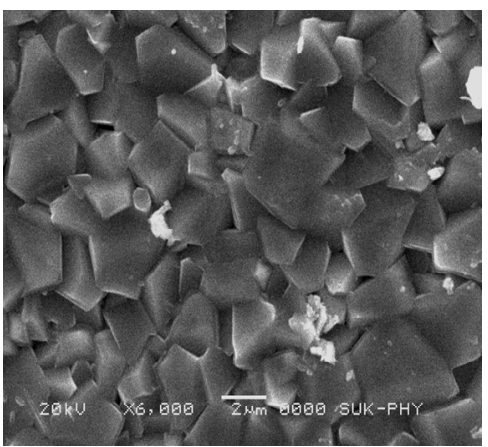

(f)

Figure 3. SEM of series $\mathrm{Li}_{0.35} \mathrm{Cd}_{\mathrm{x}} \mathrm{Ti}_{\mathrm{x}} \mathrm{Mn}_{0.1} \mathrm{Fe}_{2.55-2 \mathrm{x}} \mathrm{O}_{4}$ with $\mathrm{x}=\mathbf{0}$ to 0.5 .

Variation of $\log \rho$ vs $10^{3} / \mathrm{T}$ for the samples $\mathrm{Li}_{0.5} \mathrm{Cd}_{\mathrm{x}} \mathrm{Ti}_{\mathrm{x}}$ $\mathrm{Mn}_{0.1} \mathrm{Fe}_{2.55-2 \mathrm{x}} \mathrm{O}_{4}$ and $\mathrm{Li}_{0.35} \mathrm{Cd}_{\mathrm{x}} \mathrm{Ti}_{\mathrm{x}} \mathrm{Mn}_{0.1} \mathrm{Fe}_{2.55-2 \mathrm{x}} \mathrm{O}_{4}$ with $\mathrm{x}=$ $0,0.1,0.2,0.3,0.4$, and 0.5 are shown in Figure 5. All the plots exhibit a linear relationship suggesting that the resistivity obeys a relation $\rho=\rho_{0} \exp (\Delta \mathrm{E} / \mathrm{kT})$ and change in slope is observed in case of all the compositions. From figure, it is seen that the variation is almost linear up to Curie temperature where a break occurs indicating a change of magnetic ordering from ferrimagnetic to paramagnetic. The temperatures where breaks occur coincide with the Curie temperature determined by permeability measurements which is not reported here. The exponential increase in resistivity on decrease in temperature is due to decrease in thermally activated mobility of the charge carrier. The change in slope is attributed to the change in the activation energy due to phase transition of the material from ferromagnetic to paramagnetic state. This anomaly strongly supports the influence of magnetic ordering upon the conductivity process in-ferrites. Many workers have studied $\log \rho$ vs $(1 / \mathrm{T})$ and observed similar behaviour suggesting that resistivity obeys the Arrhenius relation $[11,18]$. Resistivity studies show that resistivity $\left(\rho_{\mathrm{dc}}\right)$ of the samples in the compositions increase as the $\mathrm{Cd}^{2+}, \mathrm{Ti}^{4+}$ concentration increases similar to that reported in 10 and 11 D.C. resistivity of Li-Cd-Ti ferrite can be explained on the basis of a model based on phonon assisted electron hopping. Trace amount of $\mathrm{Fe}^{2+}$ ions are present in the present ferrites. The electrons are known to participate in the exchange process by the following reaction $\mathrm{Fe}^{2+} \leftrightarrow \mathrm{Fe}^{3+}+$ e. Hence these electrons are strongly coupled to the lattice and tunnel from one site to the other due to phonon induced transfer mechanism. $\mathrm{Ti}^{4+}$ ions, being tetravalent, localize $\mathrm{Fe}^{2+}$ ions in the system and tunneling of electrons by transfer mechanism is retarded due to the reduction of $\mathrm{Fe}^{3+}$ ions which enhances the resistivity. The activation energy is estimated to be $0.21 \mathrm{eV}$, which in turn confirms the conduction in present ferrites are due to small polarons [18].

The dielectric constant decreases with increase in frequency showing dielectric dispersion as depicted in Figure 6. The decrease in $\varepsilon$ with frequency is natural because of the fact that any species contributing to polarizability is found to show lagging behind the applied Li-Cd-Ti ferrite can be explained on the basis of a model based on phonon assisted electron hopping. Traceamount of $\mathrm{Fe}^{2+}$ ions is present in the present ferrites. The electrons are known to participate in the exchange process by the following reaction $\mathrm{Fe}^{2+} \leftrightarrow \mathrm{Fe}^{3+}+$ e. Hence these electrons are strongly coupled to the lattice and tunnel from one site to the other due to phonon induced transfer mechanism. $\mathrm{Ti}^{4+}$ ions, being tetravalent, localize $\mathrm{Fe}^{2+}$ ions in the system \& tunneling of electrons by transfer mechanism is retarded due to the reduction of $\mathrm{Fe}^{3+}$ ions which enhances the resistivity. The activation energy is estimated to be $0.21 \mathrm{eV}$, which in turn confirms the conduction in present ferrites are due to small polarons [18]. 


\section{Conclusion}

The $\mathrm{Li}_{0.35} \mathrm{Cd}_{\mathrm{x}} \mathrm{Ti}_{\mathrm{x}} \mathrm{Mn}_{0.1} \mathrm{Fe}_{2.55-2 \mathrm{x}} \mathrm{O}_{4}$ system has been successfully prepared with standard ceramic technique. The most intense (311) peak in XRD pattern confirms the formation of cubic spinel ferrite. The SEM micrograph shows the agglomerated grain structure with sharp grain

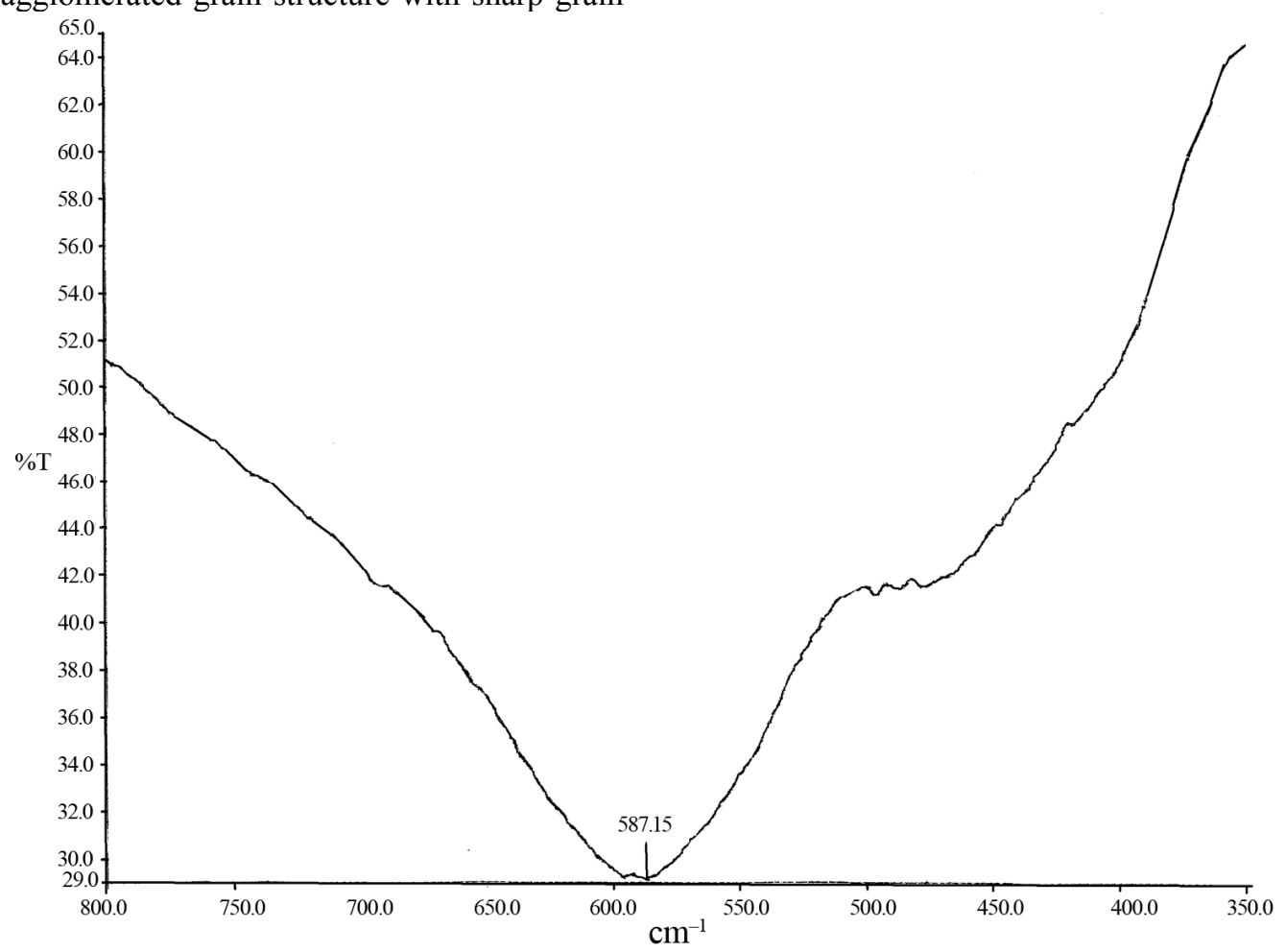

Figure 4. IR spectra of $\mathrm{Li}_{0.35} \mathrm{Cd}_{\mathrm{x}} \mathrm{Ti}_{\mathrm{x}} \mathrm{Mn}_{0.1} \mathrm{Fe}_{2.55-2 \mathrm{x}} \mathrm{O}_{4}$ with $\mathrm{x}=0.3$.

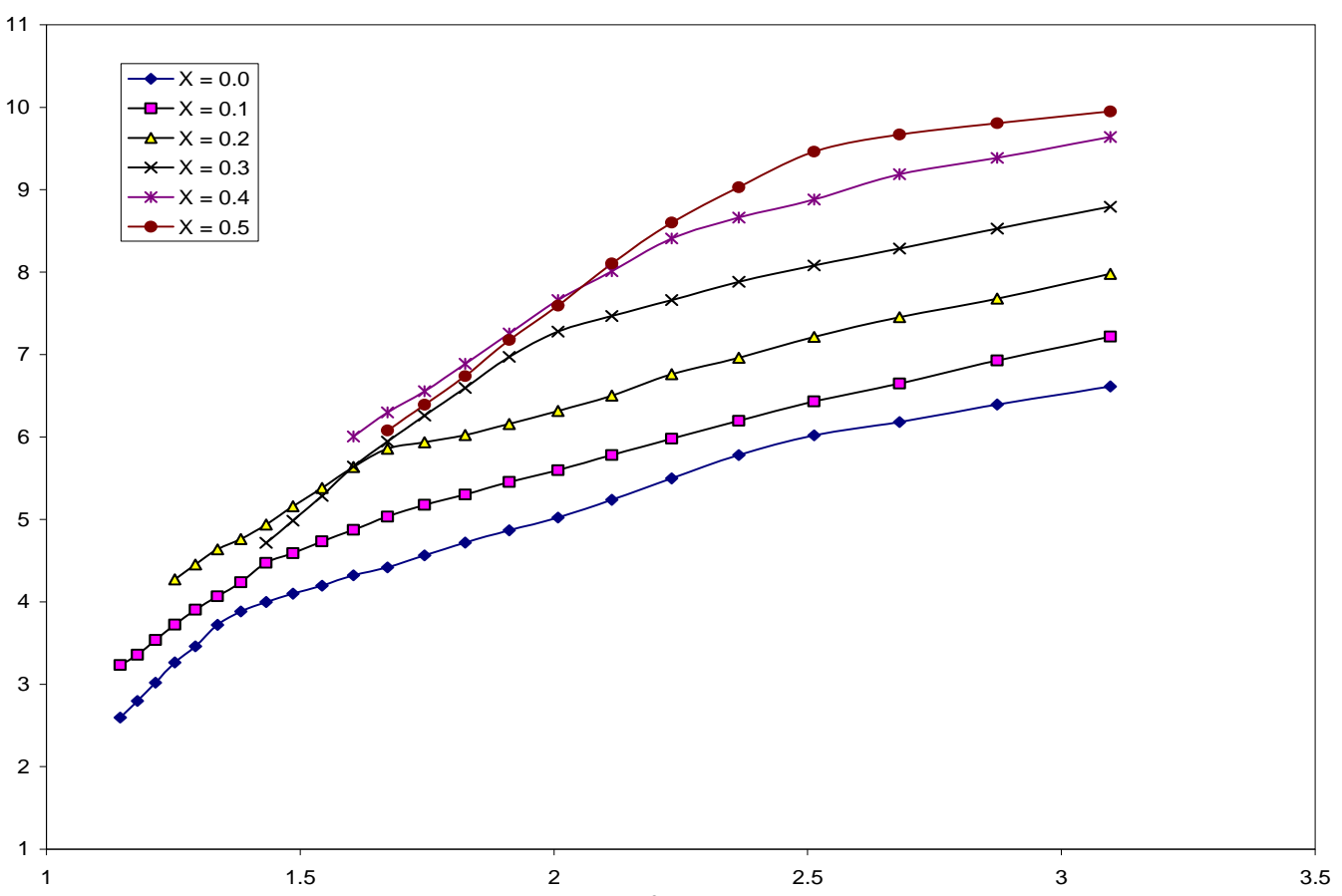

Figure 5. Variation of $\log \rho$ vs $10^{3} / \mathrm{T}$ for $\mathrm{Li}_{0.35} \mathrm{Cd}_{\mathrm{x}} \mathrm{Ti}_{\mathrm{x}} \mathrm{Mn}_{0.1} \mathrm{Fe}_{2.55-2 \mathrm{x}} \mathrm{O}_{4}$. boundaries due to high sintering temperature. The IR studies show the absorption bands which are in good agreement to the studied literature. The electrical properties study shows the Li-ferrites are the n-type semiconductors. The dielectric constant shows usual dispersion behaviour. 


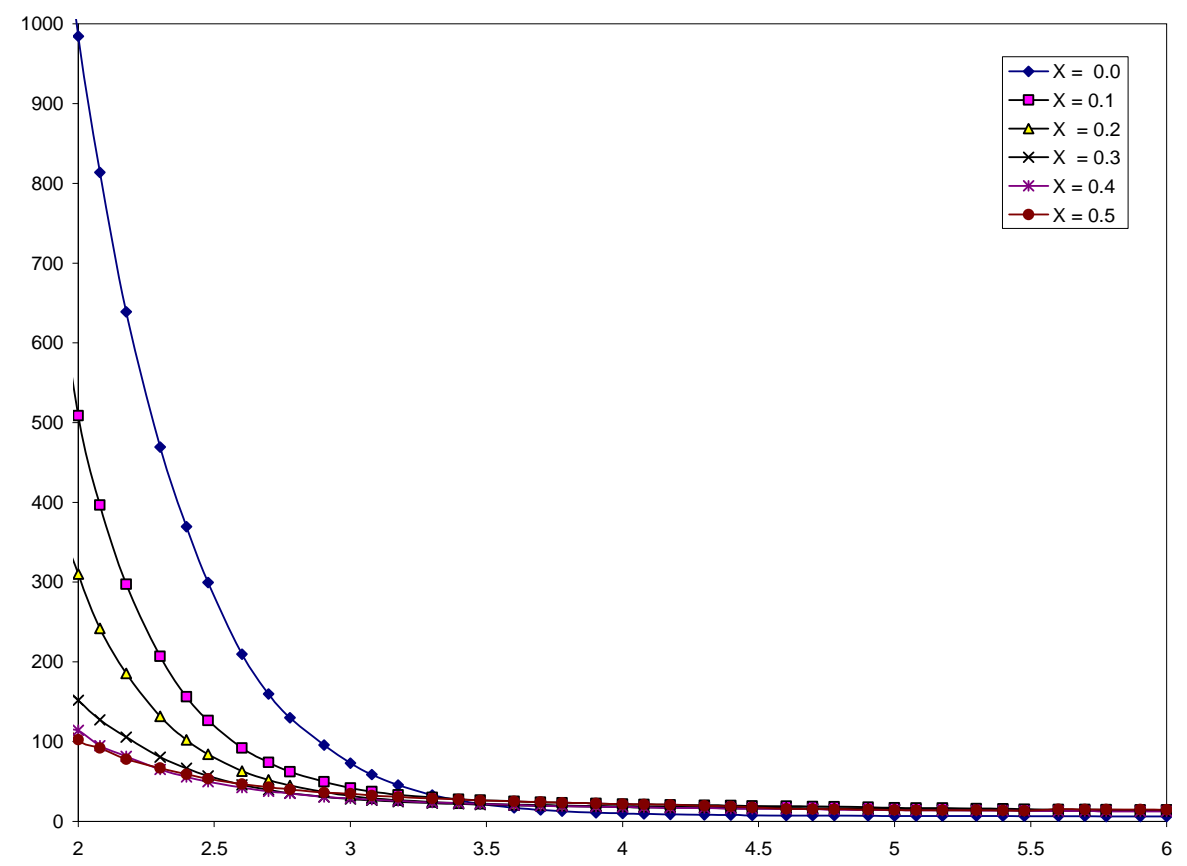

Figure 6. Variation of dielectric constant $C$ vs logf for ferrite system $\mathrm{Li}_{0.35} \mathrm{Cd}_{\mathrm{x}} \mathrm{Ti}_{\mathrm{x}} \mathrm{Mn}_{0.1} \mathrm{Fe}_{2.55-2 \mathrm{x}} \mathrm{O}_{4}$.

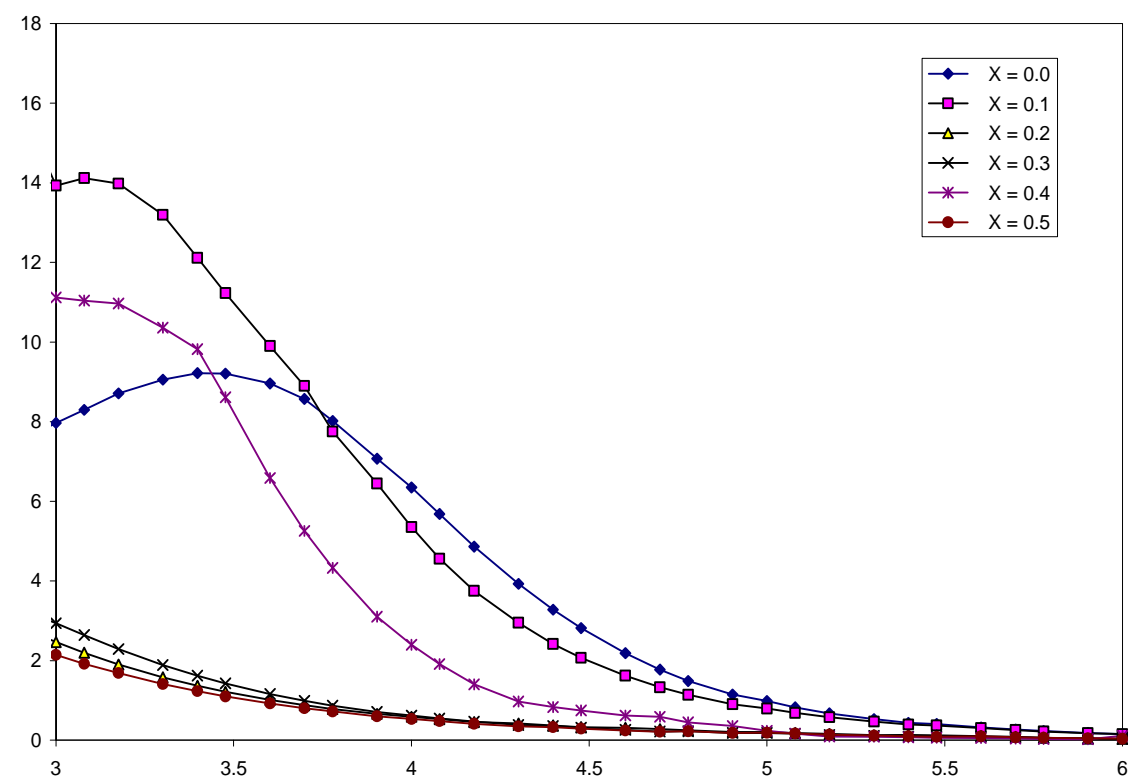

Figure 7. The plot of dielectric loss tangent $(\tan \delta)$ vs logf for ferrite system $\mathrm{Li}_{0.35} \mathrm{Cd}_{\mathrm{x}} \mathrm{Ti}_{\mathrm{x}} \mathrm{Mn}_{0.1} \mathrm{Fe}_{2.55-2 \mathrm{x}} \mathrm{O}_{4}$.

\section{Acknowledgements}

Author K. K. Patankar is thankful to UGC, New Delhi for the financial assistance in the form of major research project extended to her.

\section{REFERENCES}

[1] R. G. Kharabe, R. S. Devan, C. M. Kanamadi and B. K. Chougule, "Dielectric Properties of Mixed Li-Ni-Cd Ferrites," Smart Materials and Structures, Vol. 15, No. 2, 2006, pp. 229-334. doi:10.1088/0964-1726/15/2/N02
[2] S. R. Sawant, D. N. Bhosale, N. D. Chaudhari and P. P. Bakare, "Electric Properties of NiCuZn Ferrites Synthesized by Oxalate Precursor Method," Journal of Materials Science, Vol. 3, 2002, pp. 617-622.

[3] B. P. Ladgaonkar, P. N. Vasambekar and A. S. Vaingankar, "Structural and DC Electrical Resistivity Study of $\mathrm{Nd}^{+}$Substituted Zn-Mg Ferrites," Journal of Materials Science Letters, Vol. 19, No. 5, 2000, pp. 1375-1377. doi:10.1023/A:1006713518433

[4] M. Pardavi-Horvath, "Microwave Applications of Soft Ferrites," Journal of Magnetism and Magnetic Materials, Vol. 215-216, 2000, pp. 171-183. 


\section{doi:10.1016/S0304-8853(00)00106-2}

[5] V. Voronkov, "Microwave Ferrites: The Present and Future," Journal of Physics IV (Paris), Vol. 7, No. 1, 1997, pp. 35-38.

[6] D. Ravinder, "Dielectric Behaviour of Lithium-Cadmium Ferrites," Physica Status Solidi (A), Vol. 129, No. 2, 1992, pp. 549-554. doi:10.1002/pssa.2211290225

[7] S. S. Bellad, S. C. Watawe and B. K. Chougule, "Some Ac Electrical Properties of Li-Mg Ferrites," Materials Research Bulletin, Vol. 34, No. 7, 1999, pp. 1099-1106. doi:10.1016/S0025-5408(99)00107-5

[8] V. P. Reddy and D. V. Reddy, "Far-Infrared Spectral Studies of Some Lithium-Nickel Mixed Ferrites," Journal of Magnetism and Magnetic Materials, Vol. 136, No. 3, 1994, pp. 279-283. doi:10.1016/0304-8853(94)00321-1

[9] P. P. Hankare, R. P. Patil, U. B. Sankpal, S. D. Jadhav, I. S. Mulla, K. M. Jadhav and B. K. Chougule, "Magnetic and Dielectric Properties of Nanophase Manganese-Substituted Lithium Ferrite," Journal of Magnetism and Magnetic Materials, Vol. 321, No. 19, 2009, pp. 2977-3372. doi:10.1016/j.jmmm.2009.05.074

[10] R. G. Kharabe, R. S. Devan and B. K. Chougale, "Structural and Electrical Properties of Cd-Substituted Li-Ni Ferrites," Journal of Alloys and Compounds, Vol. 463, No. 1-2, 2008, pp. 67-72.

[11] D. Kothari, S. Phanjoubam and J. S. Baijal, "Electrical Conduction and Dielectric Behaviour of the Oxidic Spinel $\mathrm{Li}_{0.5+0.5 \mathrm{x}} \mathrm{Cr}_{0.3} \mathrm{Ti}_{\mathrm{x}} \mathrm{Fe}_{2.2-1.5 \mathrm{X}} \mathrm{O}_{4}$," Journal of Materials Science, Vol. 25, No. 12, 1990, pp. 5142-5146. doi:10.1007/BF00580142

[12] S. Chander, M. P. Sharma, A. Krishnamurthy and B. K. Srivastava, "Mössbauer Study of Nano-Particles of Spinel Ferrites $\mathrm{Li}_{\mathrm{x}} \mathrm{Fe}_{3-\mathrm{x}} \mathrm{O}_{4}$," Indian Journal of Pure and Applied Physics, Vol. 45, No. 10, 2007, pp. 816-821.
[13] K. P. Chaea, J. G. Lee, H. S. Kweona and Y. B. Lee, “The Crystallographic, Magnetic Properties of Al, Ti Doped $\mathrm{CoFe}_{2} \mathrm{O}_{4}$ Powders Grown by Sol-Gel Method," Journal of Magnetism and Magnetic Materials, Vol. 283, No. 1, 2004, pp. 103-108. doi:10.1016/j.jmmm.2004.05.010

[14] K. K. Patankar, "Synthesis and Characterization of Magnetoelectric Composites," Ph.D. Thesis, Shivaji University, Kolhapur, 2000.

[15] A. F. Junior, E. C. de O. Lima, M. A. Novak and P. R. Wells, "Synthesis of Nanoparticles of $\mathrm{Co}_{\mathrm{x}} \mathrm{Fe}_{(3-\mathrm{x})} \mathrm{O}_{4}$ by Combustion Reaction Method," Journal of Magnetism and Magnetic Materials, Vol. 308, No. 2, 2007, pp. 198202. doi:10.1016/j.jmmm.2006.05.022

[16] B. K. Bammannavar, L. R. Naik, R. B. Pujar and B. K. Chougule, "Preparation, Characterization and Physical Properties of Mg-Zn Ferrites," Indian Journal of Pure and Applied Physics, Vol. 14, No. 5, 1998, pp. 381-385.

[17] P. V. Redy and V. D. Reddy, "Far-Infrared Spectral Studies of Some Lithium-Nickel Mixed Ferrites," Journal of Magnetism and Magnetic Materials, Vol. 136, No. 3, 1994, pp. 279-283. doi:10.1016/0304-8853(94)00321-1

[18] R. S. Patil, S. V. Kakatkar, S. A. Patil, P. K. Maskar and S. R. Sawant, "Electrical Properties of Ferrites," Indian Journal of Pure and Applied Physics, Vol. 29, 1991, pp. 131-135.

[19] V. P. Reddy and D. V. Reddy. "Far-Infrared Spectral Studies of Some Lithium-Nickel Mixed Ferrites," Journal of Magnetism and Magnetic Materials, Vol. 136, No. 3, 1994, pp. 279-283. doi:10.1016/0304-8853(94)00321-1

[20] S. A. Rahman, "Temperature, Frequency and Composition Dependence of Dielectric Properties of Nb Substituted Li Ferrite," Egyptian Journal of Solids, Vol. 29, No. 1, 2006, pp. 131-141. 